\title{
ERP Systems and User Perceptions: An Approach for Implementation Success
}

\author{
Xavier Thavaruban Thavapragasam \\ Griffith University, Nathan, Australia.
}

xavier@g2gm.com

\begin{abstract}
The growth of Enterprise Resource Planning (ERP) systems since the 90's has been immense. Their organisational wide functionality is vast and overall capabilities are enormous but their success, usability and the user perception is questioned in the information systems (IS) literature. This paper looks at an implemented ERP system in a large Australian University. The core aspect of the paper is the user perception on the implemented system, which is measured by two criterions: user satisfaction and post-implementation factors. The author is using interviews, documentary analysis and observation techniques for data gathering. Based on the gathered findings, the author portrays the use of participatory design (PD) methods as a possible tool for successful ERP implementation. User-Centred Design (UCD) and Joint Application Development (JAD) were compared as part of the PD approach and it was concluded that the UCD approach would best suit for the development and the implementation of an ERP system.
\end{abstract}

Keywords: ERP Implementation, User Satisfaction, PD, UCD, JAD

\section{Introduction}

The notion of ERP implementation success, the usability of ERP systems and the user perception of the ERP system is widely discussed in the IS literature. The dawn of ERP systems have brought many changes among small to medium businesses, large organisations and educational institutions across the globe. It has brought changes not only to the technical perspective on the development of enterprise wide systems but also changes to organisational structure, processes and culture. These changes raised questions regarding usability and user perception of ERP systems. Jokela (2001) suggests usability as one of the most important quality characteristics of software intensive systems and products.

This paper addresses the importance of ERP implementation within an organisation, primarily within an educational institution and addresses the issues related with the usability and the user perception on an implemented ERP system. The research project discussed in this paper is derived from an implemented ERP system in a large Australian University. The system examined in this paper is the PeopleSoft Student Administration Module and the selected users for this system are staff from Student Administration Centre.

Material published as part of this journal, either on-line or in print, is copyrighted by Informing Science. Permission to make digital or paper copy of part or all of these works for personal or classroom use is granted without fee provided that the copies are not made or distributed for profit or commercial advantage AND that copies 1) bear this notice in full and 2) give the full citation on the first page. It is permissible to abstract these works so long as credit is given. To copy in all other cases or to republish or to post on a server or to redistribute to lists requires specific permission from the publisher at Publisher@InformingScience.org
While discussing ERP implementation, the author suggests the use of PD methods such as UCD and JAD as a tool for successful development and implementation of ERP systems. A comparison is performed between UCD and JAD to find the most appropriate method to be used for ERP sys- 
tem development and implementation. The research takes a qualitative research approach and uses idiographic methods such as interviews, observations and documentary analysis for data gathering. Moreover, the NUD*IST software tool and triangulation techniques are used for data analysis. It is important to note that while the comparison is performed, the notion of product usability is addressed.

\section{The ERP Phenomena}

\section{What is ERP?}

It is said that ERP is the finest expression of the inseparability of business and information technology (Gupta, 2000). ERP systems emphasize one specific theme: integration of all organisational processes and this has enticed many organizations to adopt ERPs in recent year (Sia, Tang, Soh, \& Boh, 2002). According to Gupta (2000) ERP allows companies to integrate various departmental information and for many users, an ERP is a "do it all" system that performs everything from entry of sales orders to customer service.

Moreover, an ERP-system enables companies to integrate data used throughout the whole organization and embraces operation and logistic, procurement, sales and marketing, human resource and financial modules (Wassenaar, Gregor, \& Swagerman, 2002). ERPs are often touted as offthe-shelf IT solutions that will enable organizations to achieve faster cycle ties, reduced costs, and improved customer service (Sia, et al., 2002). Wassenaar, et al. (2002) continues to suggest that ERP-system implementation implies a much stronger organizational change that normal information system development.

Problems associated with software implementations are not new, nor specific to enterprise resource planning (ERP) systems (Scott \& Vessey, 2000). However defining problems associated with ERP implementation can vary and the following section outlines some of the problems identified in Australian educational institutions.

\section{ERP Implementation \& Outcomes}

The theme of ERP implementation failures has been a major topic of discussion (Thavapragasam, 2003) and according Boston Consulting Group (2000), only one in three ERP initiatives was considered a success. The author is focusing on the failures rather than the success stories since the whole purpose of this paper is to derive a PD methodology for successful ERP development and implementation in educational institutions. Addressed below are some ERP initiatives conducted by different Australian Universities and the reasons for their failures. The ERP systems used in these Universities are PeopleSoft systems and it aligns evenly with the theme of this paper since the author is assessing a PeopleSoft system in a different Australian University. Thus, it will allow the author to perform a comparison between UCD and JAD based on the findings gathered from the undertaken research. The names of the Universities are not mentioned due to confidentiality reasons.

- ERP Failure \#1: Staff had problems accessing financial information and the functionality of the system was blamed for the failure (Brown, 2002).

- ERP Failure \#2: Accessing information was hard and the functionality issues were blamed for the failure (Brown, 2002).

- ERP Failure \#3: Functionality problems with the system. The University had to take funding from money that was aimed for other research areas to support the implementation project (Madden, 2002; Moodie, 2002b, cited in Nielsen, 2002). 
- ERP Failure \#4: First University to implement all three modules of PeopleSoft in Australia but it was reported over budget and the staff not happy with the benefits of system vs. cost of the system (Lawnham, 2001).

The reasons for the ERP failures in these educational institutions definitely raise questions regarding ERP systems functionality, usability, adaptability, user satisfaction and even return on investment, which all organisations thrive for. According to Ranganathan and Samarah (2001), the reported failures of ERP systems by companies such as FoxMeyer Drugs, Applied Materials, Hershey, Mobil Europe, and Dow Chemicals have questioned the very viability of ERP systems.

\section{Participatory Design \& Co-existing Approaches}

Success of information systems development can be measured by number of different criteria. However, involvement of developers and users during the system development are vital for its success. According to Bostrom and Anson (1988) developing an information system (IS) requires the cooperation or participation of multiple experts, including functional users and IS technical specialists. As cited in Beekhuyzen, von Hellens, Morley, \& Nielsen (2003) PD methods have a common concern for the "knowledge, voices, and/or rights of end-users" (Muller, 1993) and hence, this section defines PD and two of its most promising PD approaches: UCD and JAD.

Allen et al. (1993) state that PD is a body of practice and theory that emphasizes direct, empowered, collaborative action by users, in concert with software professionals. The purpose of PD and its co-existing approaches are to develop and implement easy to use and user interactive systems. Developing and implementing ERP systems and satisfying users would be an in-formidable task. Thus, using PD methods such as UCD and JAD can be beneficial for organisations implementing ERP systems or even large complex systems. There already exist international standards to facilitate PD methods such as the ISO 13407 (1999) and ISO TR 18529 (2000). Adding to these standards are the PD methods such as UCD and JAD, which will be compared and discussed in this paper.

Ives and Olson (1984) cited in Bostrom and Anson (1988) provide two major reasons for user involvement found in IS design literature:

- Improved system quality through more accurate and complete information requirements; providing expertise not available in IS groups; avoiding development of unacceptable or unimportant features; and improving user understanding of the system.

- Increased user acceptance of the system through the development of realistic expectations; providing an arena for bargaining and conflict resolution about design issues; promoting user ownership; decreasing resistance to change; and committing users to the system.

\section{User-Centred Design}

First of the PD method to be discussed in this paper is User-Centred Design or UCD for short. UCD refers to multi-disciplinary design approach based on the active involvement of users for a clear understanding of user and task requirements, and the iteration of design and evaluation (Mao \& Vredenburg, 2001). According to Beekhuyzen et al. (2003) UCD is a well established design approach that has been widely adopted by many organisations to deliver products that meet users' expectations. Proper application of UCD can lead to user satisfaction with the usability of the developed product or system and the international standard IS0 13407 (1999) outlines some of the benefits of usability:

- Increased Productivity 
- Enhanced quality of work

- Improved user satisfaction

- Reductions in support and training cost

The key focus of UCD is the user play a critical role in the design of easy-to-use products throughout the entire development process (Vredenburg, Isensee, \& Righi, 2002). Even though, there are different international standards and different approaches for UCD, they all incorporate the underlying and the basic principles for developing and implementing usable products and interactive systems.

Vredenburg, Isensee and Righi (2002) state in their book that making the transition from traditional design and development approaches to UCD usually involves a major cultural transformation for an organization and a paradigm shift for practitioners. Further, they have developed the six core UCD principles that communicate the essence of UCD and serve as a framework for individual methods and techniques. While the different international standards and different approaches are acknowledged as important UCD methods, the author believes the above mentioned six core principles are vital for successful development of usable products and systems. The six principles as follows:

- Set business goals. Determining the target market, intended users, and primary competition is central to all design and user participation.

- Understand users. An understanding of the user is the driving force behind all design.

- Design the total customer experience. Everything a customer sees, hears, and touches is designed together by a multidisciplinary team.

- Evaluate design. User feedback is gathered often with rigor and speed and drives product design.

- Assess competitiveness. Competitive design requires a relentless focus on the way users currently carry out the tasks and a determination to make designs add value.

- Manage for Users. User feedback is integral to product plans, priorities, and decisionmaking.

\section{Joint Application Development}

JAD, also referred as Joint Application Development, was developed by IBM Canada in the late 1970s (Chin, 1995). JAD is a management process - a people process - which allows IS to work more effectively with users in a shorter time frame (Jennerich, 2003). According Nickolett (2003) JAD offers a time-tested method for handling the business and administrative challenges in requirements gathering - not the theoretical, but the real works issues confronting developers. While comparing other PD methods with JAD is some what different in the end goals, in that if focuses on the functional requirements rather than the social aspects (Carmel, Whitaker, \& George, 1993).

Chin (1995) portrays the JAD technique as a structured meeting approach that provides an environment for clients and software engineers to work together as a team to share information and ideas through brainstorming sessions throughout the development life cycle. Since the late seventies, JAD has proven to be an effective technique for building user commitment to the success of application system through their active participation in the analysis of requirements and the specification of the system design (Jennerich, 2003). 
JAD meetings are structured and are led by a facilitator who is ideally familiar with group dynamics and techniques for managing meetings (Chin, 1995). All methods and approaches have their own unique way of achieving the end goals. Like the UCD's six core principles (see previous section), the JAD has its unique approach which is the five phases as addressed by Carmel, Whitaker and George (1993). The five phases of JAD as follows:

- Project Definition: Includes defining the project's purpose, scope, and objectives, identifying JAD team members, setting schedules etc.

- Research: This phase involves gathering more details about the user requirements, exploring problem domain, considering design issues etc. Based on the research, an agenda is prepared listing what needs to be decided in the session.

- Preparation. This phase involves preparing all session tools, such as visual aids, working document, flip charts, and overhead transparencies.

- The Session: This is the actual workshop session. JAD team members define business processes, project requirements, etc. Agreed-upon decisions are documented for the final phase.

- The Final Document: The information captured in the session is used to produce the final document. This is the final product of JAD sessions.

The power of JAD is in the integration of behavioral and group dynamics techniques within the structure of a soundly engineered methodology (Jennerich, 2003).

\section{Context of Research}

This section provides a detailed description of the research fundamentals. The research goals section describes the purpose of the research and identifies the research questions. Followed by research methodology describing the research approach and how the research is carried out. Finally, the adapted research framework will be used to guide the research.

\section{Research Goals}

As mentioned previously in the introduction, the purpose of this paper is using an ERP implementation scenario to identify usability and user acceptance. More specifically, to explore the user acceptance of the system and to propose PD methods such as UCD and JAD as possible approaches for successful ERP development and Implementation. Attempting to achieve these research goals will involve answering the following research questions:

What is the status level of user acceptance on the implemented ERP system with regards to user satisfaction and post-implementation factors?

How PD methods such as UCD and JAD could be used for successful ERP development and implementation?

What is the most appropriate PD method should have been used for successful development and implementation of ERP system for this particular research scenario?

\section{Research Methodology}

This research takes a qualitative research approach and used idiographic methods as for means of gathering data are used in this research are interviews, documentary analysis and observation techniques. These three methods are used to find answers for the three criteria used to explore the user acceptance level on the implemented ERP system. However, the one-to-one interviews with 
the users specifically target the two criteria, which are user satisfaction and the postimplementation factors thus validating the acceptance level.

The gathered data is analysed manually and with the aid of a NUD*IST software tool specifically designed for qualitative data analysis purposes. In addition, Jick's (1979) triangulation technique is used to analyse and validate the gathered data.

\section{Research Framework}

Due to the comparison technique used in this paper, the author has decided not to use any developed and recognised frameworks for this research. Rather, the author has developed the visual representation of the research process shown in Figure 1.

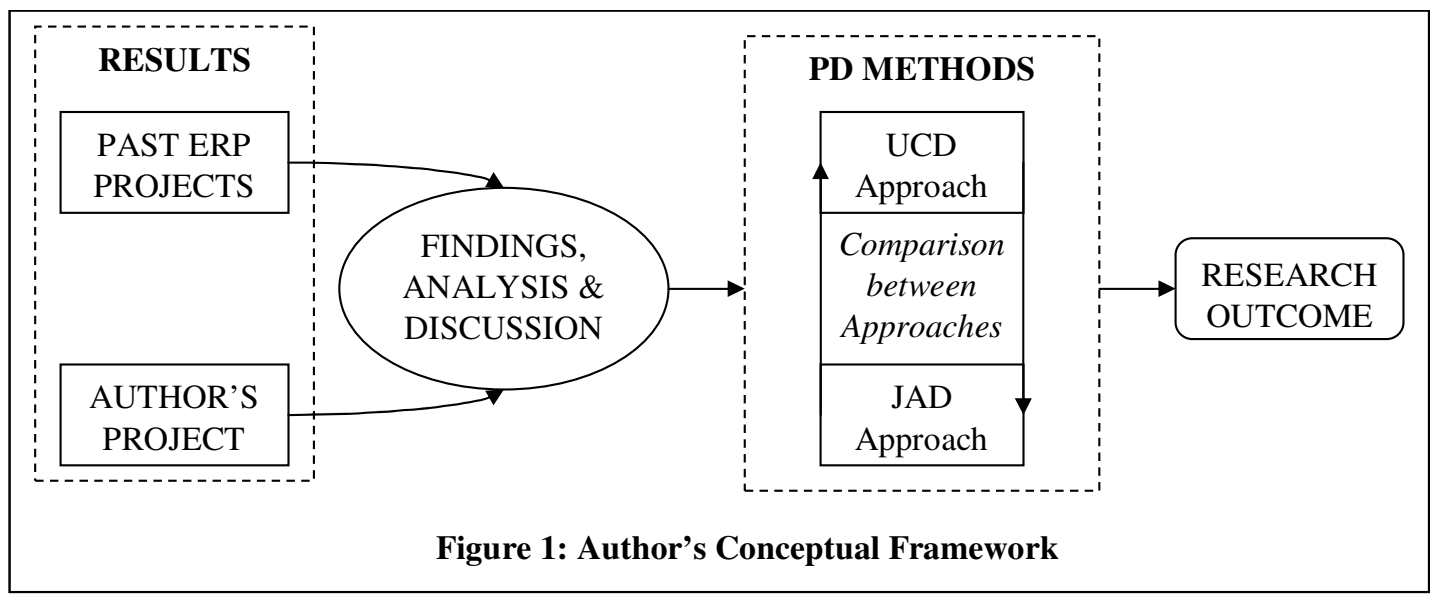

As Figure e depicts, the research framework is divided into four separate sections. Firstly, the results section contains results from the past ERP projects in Australian educational institutions and the current research project, which is the GU ERP project. The gathered results is then analysed in the findings and analysis section. Followed by the PD methods, which perform a comparison between UCD and JAD, approaches based on the findings gathered from the previous findings and analysis section. Finally, the research outcome section describes the most appropriate PD method to be used in educational institutions during ERP development and implementation.

\section{Results \& Findings}

Results and the findings section is dedicated for the current research on the user perception of the implemented ERP system at an Australian University. Three methods used for data gathering are one-to-one interviews, documentary analysis and observations. The primary and the most influential data-gathering medium were the interviews held with the current users of the system. 9 users from the selected research site were interviewed who uses the system for everyday work practices. For the purpose of this research, this section is divided into two folds according to the specified criteria.

\section{Criteria 1: User Satisfaction}

The results addressed in this section are based on the user perception criteria 1, user satisfaction. For confidentiality reasons, the names of the interviewed person will not be given however a unique user ID is allocated for each user. There were ten CIS were working at the time of the interviews but one of the user decided not to take part in the interview process and thus "User 1" is 
missing from Table 1 . Ttable 1 addresses some of the comments made by users regarding their satisfaction with the system and their responses are based on the following two attributes:

User Satisfaction Rating: Users' overall satisfaction with the system on a scale of $1-5$ where 1 is 'I hate it' and 5 is 'I like it'.

User Perception: Users' perception on specific issues such as system processes, user friendliness, quality and the effectiveness of the system.

Table 1: Results Gathered for Criteria 1 - User Satisfaction

\begin{tabular}{|c|c|c|}
\hline User ID & $\begin{array}{c}\text { User Satisfaction } \\
\text { Rating }\end{array}$ & User Perception \\
\hline & Scale of 1 - 5 & \\
\hline User 2 & 2.5 & $\begin{array}{l}\text { "It seems to me that the system is bit, a little bit clunky } \\
\text { (useless) in terms of processes. So it seems to be, the lot } \\
\text { of the processes are fare more complicated that they } \\
\text { should be..." }\end{array}$ \\
\hline User 3 & 3.5 & "I would say 'NO' at this stage..." \\
\hline User 4 & 3 & $\begin{array}{l}\text { "Not really... not a } 100 \% \ldots \text { because of the problems ... } \\
\text { and its very frustrating" }\end{array}$ \\
\hline User 5 & 4 & $\begin{array}{l}\text { "Definitely satisfied ... but some of the navigation to get } \\
\text { to check something is bit doggy..." }\end{array}$ \\
\hline User 6 & 3 & $\begin{array}{l}\text { "Sofar ... yes... but not completely... too many proc- } \\
\text { esses and lot of procedures and rework involved." }\end{array}$ \\
\hline User 7 & 5 & $\begin{array}{l}\text { "Hmm... the system is effective... I often this that... it's } \\
\text { not the system that fails, it's the person who is brining } \\
\text { the information..." }\end{array}$ \\
\hline User 8 & 4 & $\begin{array}{l}\text { "Yes I am... from my limited experiences... it is com- } \\
\text { prehensive database and I can see the benefit from where } \\
\text { I am working..." }\end{array}$ \\
\hline User 9 & 4 & $\begin{array}{l}\text { "No... the user friendliness of the system is absolute gar- } \\
\text { bage..." }\end{array}$ \\
\hline User 10 & 4.5 & "Not a $100 \% \ldots$ because it has room for improvement..." \\
\hline
\end{tabular}

The findings addressed in Table 1 are rather contradicting when the users of the system were questioned regarding their satisfaction with the system. This paper does not identify all the results found during the study but according to the above table, the paper does suggest the users' rating and their perception of satisfaction with the implemented ERP system. The contradicting point is that, when the users were asked for their overall satisfaction, they rated the system at an average of 3.7 out of 5 or a $74 \%$ success rate, which is quite impressive. However, when they were asked specifically for their perception on user satisfaction level, only 2 out 9 users said they are satisfied with the system, which is only a $22 \%$ success rate. The outcomes of the results are further discussed in the "Discussion and Perceptions" section. 


\section{Criteria 2: Post-Implementation Factors}

The post-implementation factor section is the second user perception criteria. The following table addresses each user and their perception on post-implementation factors. Again, due to confidentially reasons, the names of the users will not be addressed and "User 1" is missing from the table since the user decided not to take part in the interview. Table 2 addresses some of the comments made by users on the post-implementation factors affecting their work their responses are based on the following two attributes:

Factors Addressed by Users: Post-implementation factors influencing their work

User Perception: Users' overall perception on the post-implementation factors with the implemented system.

Table 2: Results Gathered for Criteria 2 - Post-Implementation Factors

\begin{tabular}{|c|c|c|}
\hline User ID & $\begin{array}{l}\text { Factors Addressed by Us- } \\
\text { ers }\end{array}$ & User Perception \\
\hline User 2 & Training & $\begin{array}{l}\text { "Training is not good as what it should be and } \\
\text { the back up support is not there..." }\end{array}$ \\
\hline \multirow[b]{2}{*}{ User 3} & Bug-free Reports & $\begin{array}{l}\text { "Bug-free finances reports because we can't } \\
\text { read it" }\end{array}$ \\
\hline & Training & $\begin{array}{l}\text { "No... I don't regard that as adequate... we } \\
\text { have struggled..." }\end{array}$ \\
\hline \multirow[t]{2}{*}{ User 4} & System Crash & $\begin{array}{l}\text { "The system goes down quite a lot and I think } \\
\text { that's the big thing and I think everyone would } \\
\text { agree with me for that..." }\end{array}$ \\
\hline & Training & "I think the training is good...' \\
\hline \multirow[b]{2}{*}{ User 5} & System Crash & "... The negative is, it goes down quite a lot..." \\
\hline & Training & $\begin{array}{l}\text { "Training was good... but they should do more } \\
\text { follow up trainings..." }\end{array}$ \\
\hline User 6 & Training & "Yes. It was helpful and adequate' \\
\hline User 7 & None expressed & Did not make any comments or suggestions. \\
\hline \multirow[b]{2}{*}{ User 8} & Doing Research & $\begin{array}{l}\text { "Doing research in terms of users' perspec- } \\
\text { tive..." }\end{array}$ \\
\hline & Feedback & $\begin{array}{l}\text { "They should find about what people thought... } \\
\text { I think every project that goes through the Uni- } \\
\text { versity always needs feedback..." }\end{array}$ \\
\hline \multirow{2}{*}{ User 9} & User Friendliness & $\begin{array}{l}\text { "User friendliness... that's the negative side to } \\
\text { it... it's not user friendly what so ever..." }\end{array}$ \\
\hline & Training & "Training is Not helpful but adequate" \\
\hline User 10 & Training & $\begin{array}{l}\text { "Some of training... is been good and some of } \\
\text { it really needs lot of work in how it pre- } \\
\text { sented..." }\end{array}$ \\
\hline
\end{tabular}




\begin{tabular}{|l|l|l|}
\hline Feedback & $\begin{array}{l}\text { "Not getting enough feedback from us... like } \\
\text { they don't come and ask us about what they are } \\
\text { doing and how it will impact us and how we } \\
\text { can think it should be done..." }\end{array}$ \\
\hline
\end{tabular}

The success of an ERP system can be judged through performing post-implementation review or an audit or from factors influencing the users to complete their everyday tasks due to the system implementation. When the users were asked what they perceive as the important postimplementation factors influencing their work, 7 out 9 users or $78 \%$ of the users identified training as a crucial factor. The overall reaction to training of the users with the new system is rather dissatisfying. User 2 suggested that "the training is not good as what it should be and the back up support is not there..." and the rest of the findings are further discussed in the up coming section.

\section{Discussion \& Perceptions}

The IS literature does suggests the failures of ERP projects and more specifically in Australian Universities (Brown, 2002; (Madden, 2002; Moodie, 2002b, cited in (Nielsen, 2002)); Lawnham, 2001). Thus discussing the results found form the IS literature on ERP projects as well as from the author's research study, the following hypothesis can be made:

Based on the author's work, only 2 out of 9 users said they are satisfied with system.

It was also found that the users seem to be mystified while identifying their satisfaction rate and this might be due to users' age, experiences with the system, how often they use the system? and for what purposes they use the system?

More over, $78 \%$ of the users identified training as one of the major factor influencing their work performances.

In addition to the training factor, users also identified system crash, user feedback, user friendliness and doing research in terms of users' perspective (User 8). While considering the problems at hand, the author is suggesting the use of UCD or JAD approaches to overcome these problems.

\section{UCD \& JAD Comparison}

Having defined UCD and JAD and their features (see Participatory Design and Co-existing Approaches section), this section will include a comparison of UCD and JAD based on the discussion on results gathered (see previous section). UCD and JAD are part of the PD method primarily developed to associate users during the system development phase. It seems the identified problems are rather social issues in nature and could be certainly overcome if the users are involved during the development of the system.

Both UCD and JAD methods can be employed to overcome the above mentioned issues however choosing of either method is depends on the problems at hand and on what level the product is developed such as social or technical perspective. The issues identified in this research are social in nature and the choosing of the method must be complied with the social issues. While comparing these two methods, the key focus of UCD is the user play a critical role in the design of easyto-use products throughout the entire development process (Vredenburg, Isensee \& Righi, 2002) but JAD is some what different in the end goals, in that if focuses on the functional requirements rather than the social aspects (Carmel, Whitaker \& George, 1993).

Considering the nature of author's research work and the problems identified by users, it seems the use of UCD method for developing successful ERP systems is much better than the JAD option. Also, the six principles of UCD design seem to be properly structured and a better developed 
approach to overcome these problems rather than the five phases of JAD. Therefore, author concludes that the use of UCD approach is better than the JAD approach for developing successful ERP projects.

\section{Final Remarks \& Future Directions}

This paper looked at an implemented ERP system in a large Australian University. The core aspect of the paper is the user perception on the implemented system, which is measured by two criteria: user satisfaction and post-implementation factors. The research involves CIS as users of the system and the implemented system under investigation is the PeopleSoft Student Administration Module. Based on the gathered findings, the author portrayed the use of PD methods as a tool for successful ERP implementation. The research found that only $22 \%$ of the users found the system to be satisfying and $78 \%$ suggested training as one of the important post-implementation factor affected their work performance. UCD and JAD methods were compared as part of the PD approach and it was concluded that the UCD approach will best suit for the development and the implementation of an ERP system.

\section{Future Directions}

This research study provides a brief overview into users' perceptions on implemented ERP system in a large Australian University and it was also concluded that the UCD approach is better than JAD while developing ERP systems. However, further and more detailed research should be undertaken to validate the use of UCD approach for future development of ERP systems. The research also identified very interesting results regarding user satisfaction however a future research should be conducted to develop a standard user satisfaction criteria to assess users' satisfaction with information systems and more specifically do assess ERP system implementation success.

\section{References}

Allen, C. D., Ballman, D., Begg, V., Miller-Jacobs, H. H., Muller, M., Nielsen, J. \& Spool, J. (1993). User involvement in the design process: Why, when \& how? ACM, April, 24-29, 251-254.

Beekhuyzen, J., von Hellens, L., Morley, M. \& Nielsen, S. (2003). Searching for a methodology for smart internet technology development. Proceedings of the Twelfth International Conference on Information Systems Development, Melbourne, Australia, August 25-27.

Bostrom, R. \& Anson, R. (1988). Using computerized collaborative work support systems to improve the logical systems design process. ACM, 98 - 108.

Brown, P. (2002). Rocky road to hi-tech admin. The Australian, Australian IT Section, 16.01.02, p. 20.

Carmel, E., Whitaker, R. D. \& George, J. F. (1993). PD and joint application design: A transatlantic Comparison. Communications of ACM, 36 (4).

Chin, K. F. (1995). A JAD experience. ACM, pp. 235 - 236.

Group, B. C. (2000). Getting value from enterprise initiatives: A survey of executives. Boston Consulting Group, pp. 1 - 25.

Gupta, A. (2000). Enterprise resource planning: The emerging organizational value systems. Industrial Management and Data Systems, 100 (3), 114 - 118.

ISO13407. (1999). Human-centred design processes for interactive systems. Geneva, Switzerland.

ISOTR18529. (2000). Ergonomics -- Ergonomics of human-system interaction -- Human-centred lifecycle process descriptions. Last Accessed: 12.10.2003. 
Jennerich, B. (2003). Joint application design: Business requirement analysis for successful re-engineering. Retrieved 12.10.2003 from http://www.bee.net/bluebird/jaddoc.htm

Jick, T. D. (1979). Mixing qualitative and quantitative methods: Triangulation in action. Administrative Science Quarterly, 24, 602 - 611.

Jokela, T. (2001). An assessment for user-centred design processes. In Proceedings of EuroSPI. Limerick Institute of Technology Press.

Lawnham, P. (2001). Software costs soar. The Australian, Australian IT Section, 22.03.01, p. 37.

Mao, J. \& Vredenburg, K. (2001). User-centered design methods in practice: A survey of the state of the art. Retrieved 12.10.2003 from http://www.cas.ibm.com/archives/2001/proceed/cascon01/pdf.mao.pdf

Nickolett, C. (2003). Joint application design (JAD)-A case study. Comprehensive Consulting Solutions, pp. 1 - 6.

Nielsen, J. (2002). Critical success factors for implementing an ERP System in a university environment: A case study from the Australian HES, Honours Dissertation, School of Computing and Information Technology, Brisbane, Australia, Griffith University.

Ranganathan, C. \& Samarah, I. (2001). Enterprise resource planning systems and firm value: An event study analysis. International Conference in Information Systems, pp. 157 - 158.

Scott, J. E. \& Vessey, I. (2000). Implementing enterprise resource planning systems: The role of learning from failure. Information Systems Frontiers, 2 (2), 213 - 232.

Sia, S. K., Tang, M., Soh, C. \& Boh, W. F. (2002). Enterprise resource planning (ERP) systems as a technology of power: empowerment or panoptic control? The DATA BASE for Advances in Information Systems, 33 (1), 23 - 37.

Thavapragasam, X. T. (2003). Cultural influences on ERP implementation success. Proceedings of the First Australian Undergraduate Students' Computing Conference, University of Melbourne, Melbourne, Australia, 23-26.09, pp. 93 - 99.

Vredenburg, K., Isensee, S. \& Righi, C. (2002). User-centered design: An integrated approach. New Jersey: Prentice Hall.

Wassenaar, A., Gregor, S. \& Swagerman, D. (2002). ERP implementations in different organisational and cultural settings. European Accounting Information Systems Conference, Copenhagen Business School, Denmark, 23-24 April 2002, pp. 1 - 15.

\section{Biography}

Mr. Thavapragasam received his bachelor's degree in Information Technology majoring in Information Systems in 2002 from Griffith University. In 2003, he continued with his Honours studies in Information Systems particularly in Enterprise Resource Planning (ERP) systems. His interests in Organisational culture and end-user satisfaction lead to his research studies and currently completing his Honours dissertation on organisational culture impact on user satisfaction with ERP systems.

In September 2003, Mr. Thavapragasam published his first conference paper in the Australian Undergraduate Students' Computing Conference in Melbourne, Australia. Later, he was invited to compose a chapter for a book, which is to be released in late 2004 by School of Computing and Information Technology, Griffith University. Web technologies and structuration theory are his other areas of interests and currently completing a course in Process Assessment \& Improvement. Even though $\mathrm{PhD}$ is in his mind, Mr. Thavapragasam is looking new ways to utilize and practice his skills and knowledge in a leading multi-national organisation. 